\title{
commentaAy How have systematic reviews and meta-analyses benefited psychiatry? ${ }^{\dagger}$ COMMENTARY ON... THE USEFULNESS AND INTERPRETATION OF SYSTEMATIC REVIEWS
}

\author{
Alex J. Mitchell
}

\begin{abstract}
Alex J. Mitchell is a consultant psychiatrist in the Department of Psycho-Oncology, Leicestershire Partnership NHS Trust and the Department of Cancer and Molecular Medicine, University of Leicester Correspondence DrAlex J. Mitchell, Department of PsychoOncology, Hadley House, Leicester General Hospital, Leicester LE5 4PW, UK. Email ajm80@le.ac.uk
\end{abstract}

${ }^{\dagger}$ See pp. 132-141, this issue.

\section{SUMMARY \\ The article by Smith et al (2016) provides a valuable summary on the usefulness and interpretation of systematic reviews. This commentary adds a discussion of confirmation bias and a summary of some of the most useful influential systematic reviews and meta-analyses in mental health.}

\section{DECLARATION OF INTEREST}

None

\section{Methodology underlying systematic reviews and meta-analyses}

As Smith et al (2016) highlight, we have seen a significant rise in the number of published papers in the field of medicine, particularly reviews and meta-analyses (Bohlin 2012). About 10\% of all published articles are reviews and $1 \%$ are metaanalyses. Systematic reviews and, in particular, meta-analyses are often highly cited. For example, meta-analyses account for as many as $20 \%$ of the most important papers published in any given year and notated by Thomson Reuters Essential Science Indicators (ESI) as 'hot papers' (Box 1). It is vital therefore that systematic reviews and meta-analyses are accurate and unbiased. Smith et al clearly describe the process of how to conduct a systematic review, focusing on key stages: formulation of a valid question; systematic identification of all the relevant studies; and critical appraisal of each study. They also provide a very nice summary of strengths and weaknesses of meta-analysis, focusing on three major factors: quality of the data-set, comparability of the underlying studies and bias. In particular, the power of any given meta-analysis is very much limited by the quality of the underlying primary studies. This is effectively the rate-limiting step, but one that is easily overlooked by readers of such studies. However, one factor that is difficult to gauge remains the enemy of the systematic review: namely, confirmation bias (Little 2008). Although Smith et al address bias, they should perhaps have emphasised a little more strongly the problem of confirmation bias and steps to avoid it. Confirmation bias is the effect whereby authors attempt to fit and interpret findings to their a priori beliefs. We are all subject to this influence, which is why some responsibility for neutrality lies with co-authors, editors and peer reviewers. An excellent example of confirmation bias in mental health is the argument for and against depression screening (Goodyear-Smith 2012).

\section{Influential systematic reviews and meta- analyses in mental health}

To complement Smith et al's excellent summary of the methodology of systematic reviews and meta-analyses, I thought it might be useful to the reader to list some highly cited examples of recent decades. To that end, I took a 'snapshot' of citations in August 2015. Two older systematic reviews, one on the Beck Depression Inventory (Beck 1988) and the other on Alzheimer's disease (Selkoe 2001), are among the top 20 most cited papers of all time in

BOX 1 Web of Science, Essential Science Indicators and hot papers

Web of Science (previously known as ISI/Web of Knowledge): a subscription-based online scientific citation indexing service maintained by Thomson Reuters

Essential Science Indicators (ESI): a comprehensive compilation of science performance statistics and science trends data based on journal article publication counts and citation data from Thomson Scientific databases

ESI hot papers: papers that receive significant numbers of citations soon after publication; the age of hot papers is measured in months rather than years and the list of hot papers is updated every 2 months: ScienceWatch.com tracks new additions to the list 
TABLE 1 Top ten most influential meta-analyses in mental health (based on Web of Science database citation count to January 2015)

\begin{tabular}{|c|c|c|c|c|}
\hline Authors & Title of paper & $\begin{array}{c}\text { Year of } \\
\text { publication }\end{array}$ & $\begin{array}{l}\text { Citations to } \\
\text { January 2015, } n\end{array}$ & $\begin{array}{l}\text { Citation rate, } \\
n / \text { year }\end{array}$ \\
\hline Farrer et al & $\begin{array}{l}\text { Effects of age, sex, and ethnicity on the association between } \\
\text { apolipoprotein E genotype and Alzheimer's disease: a meta-analysis }\end{array}$ & 1997 & 1550 & 91.2 \\
\hline Brewin et al & $\begin{array}{l}\text { Meta-analysis of risk factors for posttraumatic stress disorder in } \\
\text { trauma-exposed adults }\end{array}$ & 2000 & 1387 & 99.1 \\
\hline Anderson et al & $\begin{array}{l}\text { The prevalence of comorbid depression in adults with diabetes: a } \\
\text { meta-analysis }\end{array}$ & 2001 & 1268 & 97.5 \\
\hline DiMatteo et al & $\begin{array}{l}\text { Depression is a risk factor for noncompliance with medical treatment: } \\
\text { meta-analysis of the effects of anxiety and depression on patient } \\
\text { adherence }\end{array}$ & 2000 & 1219 & 87.1 \\
\hline Harris \& Barraclough & Suicide as an outcome for mental disorders: a meta-analysis & 1997 & 1075 & 63.2 \\
\hline Turner et al & $\begin{array}{l}\text { Selective publication of antidepressant trials and its influence on } \\
\text { apparent efficacy }\end{array}$ & 2008 & 804 & 134.0 \\
\hline Lewis et al & $\begin{array}{l}\text { Genome scan meta-analysis of schizophrenia and bipolar disorder. } \\
\text { Part Il: schizophrenia }\end{array}$ & 2003 & 785 & 71.4 \\
\hline Kirsch et al & $\begin{array}{l}\text { Initial severity and antidepressant benefits: a meta-analysis of data } \\
\text { submitted to the Food and Drug Administration }\end{array}$ & 2008 & 766 & 127.7 \\
\hline Risch et al & $\begin{array}{l}\text { Interaction between the serotonin transporter gene (5-HTTLPR), } \\
\text { stressful life events, and risk of depression: a meta-analysis }\end{array}$ & 2009 & 681 & 136.2 \\
\hline Leucht et al & $\begin{array}{l}\text { Second-generation versus first-generation antipsychotic drugs for } \\
\text { schizophrenia: a meta-analysis }\end{array}$ & 2009 & 615 & 123.0 \\
\hline Cipriani et al & $\begin{array}{l}\text { Comparative efficacy and acceptability of } 12 \text { new-generation } \\
\text { antidepressants: a multiple-treatments meta-analysis }\end{array}$ & 2009 & 511 & 102.2 \\
\hline
\end{tabular}

the field of mental health. More recent systematic reviews gaining a great deal of influence are on suicide prevention strategies (Mann 2005) and the cannabis and psychosis debate (Moore 2007). However, it is typically meta-analyses that have most impact in psychiatry. Table 1 shows the top 10 most influential systematic reviews and meta-analyses in mental health when judged by total citations using the Web of Science database citation count.

Two highly cited papers in the table looked at selective reporting in antidepressant trials: Turner et al (2008) and Kirsch et al (2008). Turner et al examined 74 studies registered with the US Food and Drug Administration (FDA) and found that, of the $31 \%$ that were not published, only one had a positive result. Kirsch et al examined both published and unpublished data from 35 trials and found that drug-placebo differences in antidepressant efficacy increased as a function of baseline illness severity, but were relatively small even for patients with severe depression, thereby fuelling the debate about the merits of antidepressants in mild depression.

Another highly cited paper Table 1 is on the genetics of severe mental illness (Lewis 2003). Ten years later a paper by Ripke and colleagues on the same topic was to be designated an ESI hot paper, i.e. one destined to be important because of its high initial citation rate (Box 1). This was a meta-analysis of genome-wide association studies of schizophrenia (8832 cases and 12067 controls) that, from replication of single nucleotide polymorphisms (SNPs), identified 22 loci associated at genome-wide significance (Ripke 2013).

Meta-analyses on the efficiency (and side-effects) of antipsychotics are also highly cited. Leucht et al (2009) initially looked at 150 double-blind short-term studies, with 21533 participants, and found that second-generation antipsychotics differ in many properties and are not a homogeneous class (Table 1). A follow-up meta-analysis of 212 trials that ranked efficacy $v$. side-effects of 15 antipsychotics became an ESI hot paper on publication (Leucht 2013). Another ESI hot paper of 2013 on a related topic was one on which I was a co-author (Mitchell 2013). This reported that across 126 studies (25692 participants)the overall rate of metabolic syndrome in patients with schizophrenia was $32.5 \%$, but in drug-naive patients who were in their first episode the rate was not appreciably higher than that in the general population.

An interesting property of well-conducted research is the ability to refute false positives, no matter how much they are discussed. One good example, included in Table 1, relates to the serotonin transporter gene, widely purported in 
the 1990 s to be a risk for depression. In 2009, Merikangas's group (Risch 2009) found that, across 14 studies (including 10 with individual patient data), stressful life events were linked with depression (odds ratio $\mathrm{OR}=1.41$ ), but the serotonin transporter gene was not.

\section{Conclusions}

Systematic reviews and meta-analyses have established themselves as one of the most important ways for readers to keep up with the medical literature. However, as Smith and colleagues describe (Smith 2016), they must be conducted with great care in order to reach reliable conclusions. Future authors of systematic reviews and meta-analyses must try to avoid confirmatory bias when conducting their studies.

\section{References}

Anderson RJ, Freedland KE, Clouse RE, et al (2001) The prevalence of comorbid depression in adults with diabetes: a meta-analysis. Diabetes Care, 24: 1069-78.

Beck AT, Steer RA, Garbin MG (1988) Psychometric properties of the Beck Depression Inventory: twenty-five years of evaluation. Clinical Psychology Review, 8: 77-100

Bohlin I (2012) Formalizing syntheses of medical knowledge: the rise of meta-analysis and systematic reviews. Perspectives on Science, 20: 273-309.

Brewin CR, Andrews B, Valentine JD (2000) Meta-analysis of risk factors for posttraumatic stress disorder in trauma-exposed adults. Journal of Consulting and Clinical Psychology, 68: 748-66.

Cipriani A, Toshiaki FA, Georgia S, et al (2009) Comparative efficacy and acceptability of 12 new-generation antidepressants: a multipletreatments meta-analysis. Lancet, 373: 746-58.

DiMatteo MR, Lepper HS, Croghan TW (2000) Depression is a risk factor for noncompliance with medical treatment: meta-analysis of the effects of anxiety and depression on patient adherence. Archives of Internal Medicine, 160: 2101-7.

Farrer LA, Cupples LA, Haines JL, et al (1997) Effects of age, sex, and ethnicity on the association between apolipoprotein $E$ genotype and Alzheimer disease: a meta-analysis. JAMA, 278: 1349-56.
Goodyear-Smith FA, van Driel ML, Arroll B, et al (2012) Analysis of decisions made in meta-analyses of depression screening and the risk of confirmation bias: a case study. BMC Medical Research Methodology, 12: 76 .

Harris EC, Barraclough B (1997) Suicide as an outcome for mental disorders: a meta-analysis. British Journal of Psychiatry, 170: 205-28.

Kirsch I, Deacon BJ, Huedo-Medina TB, et al (2008) Initial severity and antidepressant benefits: a meta-analysis of data submitted to the Food and Drug Administration. PLoS Medicine, 5(2): e45.

Leucht S, Corves C, Arbter D, et al (2009) Second-generation versus first-generation antipsychotic drugs for schizophrenia: a meta-analysis. Lancet, 373: 31-41.

Leucht S, Cipriani A, Spineli L, et al (2013) Comparative efficacy and tolerability of 15 antipsychotic drugs in schizophrenia: a multipletreatments meta-analysis. Lancet, 382: 951-62.

Lewis CM, Levinson DF, Wise LH, et al (2003) Genome scan meta-analysis of schizophrenia and bipolar disorder. Part II: schizophrenia. American Journal of Human Genetics, 73: 34-48.

Little JH (2008) Evidence-based or biased? The quality of published reviews of evidence-based practices. Children and Youth Services Review, 30: 1299-317.

Mann JJ, Apter A, Bertolote J, et al (2005) Suicide prevention strategies: a systematic review. JAMA, 294: 2064-74.

Mitchell A, Vancampfort D, Sweers K, et al (2013) Prevalence of metabolic syndrome and metabolic abnormalities in schizophrenia and related disorders: a systematic review and meta-analysis. Schizophrenia Bulletin, 39: 306-18.

Moore THM, Zammit S, Lingford-Hughes A, et al (2007) Cannabis use and risk of psychotic or affective mental health outcomes: a systematic review. Lancet, 370: 319-28.

Ripke S, O'Dushlaine C, Chambert K, et al (2013) Genome-wide association analysis identifies 13 new risk loci for schizophrenia. Nature Genetics, 45: 1150-9.

Risch N, Herrell R, Lehner T, et al (2009) Interaction between the serotonin transporter gene (5-HTTLPR), stressful life events, and risk of depression: a meta-analysis. JAMA, 301: 2462-71.

Selkoe DJ (2001) Alzheimer's disease: genes, proteins, and therapy. Physiological Reviews, 81: 741-66.

Smith KA, Cipriani A, Geddes JR (2016) The usefulness and interpretation of systematic reviews. BJPsych Advances, 22: 132-141.

Turner E, Matthews AM, Linardatos E, et al (2008) Selective publication of antidepressant trials and its influence on apparent efficacy. New England Journal of Medicine, 358: 252-60. 